\author{
ANDRZEJ RADZIMIŃSKI \\ Uniwersytet Mikołaja Kopernika w Toruniu \\ E-Mail: ar@umk.pl
}

\title{
DIE PFARRKIRCHE ST. JOHANNES DES TÄUFERS UND ST. JOHANNES DES EVANGELISTEN \\ IN DER SAKRALTOPOGRAFIE DER STADT THORN IM MITTELALTER*
}

$\mathrm{Zu}$ dem Forschungsbereich der Sakraltopografie ${ }^{\star}$ gehört vor allem die räumliche Darstellung von Kirchen, Klöstern, Hospitälern und anderen kirchlichen Institutionen, die sich sowohl in den Städten als auch in den Vorstädten entwickelten. Mit meinem Beitrag bezwecke ich, die Johannis-Pfarrkirche in Thorn auf dem Hintergrund der anderen kirchlichen Institutionen, gelegen sowohl innerhalb der Mauern der Alt- und Neustadt wie auch in den Vorstädten, darzustellen ${ }^{1}$.

* Der Beitrag bildet eine verbesserte und ergänzte Fassung des Textes, der in folgendem Band veröffentlicht wurde: Dzieje i skarby kościoła Świętojańskiego $w$ Toruniu, hg. v. K. Kluczwajd, M. Woźniak, (2002), S. 25-39.

1 Zur Sakraltopografie in den preußischen und livländischen Städten siehe z.B. B. Jähnig, Das Entstehen der mittelalterlichen Sakraltopographie von Elbing, „Beiträge zur Geschichte Westpreußens“, 10 (1987), S. 21-48; idem, Die Anfänge der Sakraltopographie von Riga, in: Studien über die Anfänge der Mission in Livland, hg. v. M. Hellmann, (1989), S. 123-158; idem, Die Entwicklung der Sakraltopographie von Memel im Mittelalter und in der frühen Neuzeit, in: Das Preussenland als Forschungsaufgabe. Eine europäische Region in ihren geschichtlichen Bezügen. Festschrift für Udo Arnold zum 60. 
Im Mittelalter (bis zum Jahre 1454) bestand Thorn aus zwei städtischen Selbstverwaltungskommunen: Altstadt und Neustadt. Im Spätmittelalter hatte Thorn samt Vorstädten zwischen 10.000 und 12.000 Einwohner und gehörte zu den Großen unter den Hansestädten. Die bisherigen Untersuchungen über die ethnische Struktur der Alt- und Neustadt von Thorn und ihren Vorstädten schätzen, dass über 30\% der Bevölkerung polnisch und knapp $70 \%$ deutsch war ${ }^{2}$. Ein so bedeutendes städtisches Zentrum verfügte über eine weit ausgebaute sakrale Infrastruktur mit wichtigen Pfarrkirchen an der Spitze: Dabei handelte es sich um die Pfarrkirche St. Johannes des Täufers bzw. St. Johannes des Evangelisten in der Altstadt und die St. Jakobs-Pfarrkirche in der Neustadt Thorn.

Die Sakraltopografie von Thorn im Spätmittelalter bestand aus insgesamt achtzehn Objekten, von denen sich zwölf innerhalb der Stadtmauern befanden - acht auf dem Gebiet der Altstadt: in dem südlichen Teil die schon erwähnte Johanneskirche, in dem nordwestlichen Teil die Marienkirche mit dem Franziskanerkloster; in der Nähe der Marienkirche befanden sich außerdem sechs Beginenhäuser, die aus bürgerlichen Stiftungen erwuchsen. Vier Sakralobjekte lagen innerhalb der Grenzen der Neustadt: die St. Jakobs-Pfarrkirche mit dem Zisterzienserkloster, gelegen in dem südwestlichen Teil der Stadt, und die St. Nicolai-Kirche mit dem Dominikanerkloster, die ihren Sitz in dem nordöstlichen Teil der Stadt fanden; außerdem befanden sich dort ein Hospital und die Kapelle zu St. Peter und Paul, gelegen bei der Jakobs-Kirche, darüber hinaus stand bei St. Nicolai ein Beginenhaus. Die sonstigen sechs

Geburtstag, (Einzelschriften der Historischen Kommission für ost- und westpreußische Landesforschung 20), hg. v. B. Jähnig, G. Michels, (2000), S. 209-226.

2 Dazu siehe z. B. auch die neuesten Synthesen der Geschichte Thorns: Historia Torunia, hg. v. M. Biskup, 1: W czasach średniowiecza (do roku 1454), erarbeitet v. J. Chudziakowa (et al.); ibidem, 2: U schyłku średniowiecza i w początkach odrodzenia (1454-1548), erarbeitet v. M. Biskup, (1992, 1999); K. Mikulski, Przestrzeń i społeczeństwo Torunia od końca XIV do początku XVIII w., (1999); Nowe Miasto Toruń. 750 lat od lokacji, hg. v. K. Mikulski, P. Oliński, W. Rozynkowski, (2014). 
Sakralobjekte lagen außerhalb der Stadtmauern, vier davon in der Kulmer Vorstadt, im Norden die St. Laurentius-Kirche und das Hospital, die Heilig-Kreuz-Kirche mit dem Kloster der Benediktinerinnen (bis 1414), die St. Georgs-Kirche und ein Leprosorium sowie eine Kapelle; am weitesten im Norden lag die Rockendorf-Kapelle, die der Familie des Stadtrats Rockendorf gehörte. In der Jakobs-Vorstadt, östlich der Stadt, befand sich die St. Katharina-Kapelle; die Heilig-Geist-Kirche, seit 1415, mit dem Kloster der Benediktinerinnen war südlich von der Altstadt an der Weichsel gelegen ${ }^{3}$.

Es drängt sich die Frage auf, unter welchen Aspekten diese zahlreichen Sakralobjekte interpretiert werden sollen. Kann man die Worte von Gregor von Tours paraphrasieren, welche sich auf die frühmittelalterlichen Bischofsstädte am Rhein beziehen, und in diesem Sinne auch etwas über das spätmittelalterliche Thorn aussagen: „Ecclesiae muros

${ }^{3} \mathrm{Zu}$ den Kirchen und Kapellen in Thorn allgemein siehe: T. Glemma, Dzieje stosunków kościelnych $w$ Toruniu, in: Dzieje Torunia, hg. v. K. Tymieniecki, (1933), S. 259-266; J. Fankidejski, Utracone kościoły i kaplice w dzisiejszej diecezji chełmińskiej, (1873), S. 25, 27 (St. Nikolai-Kirche), 32, 35, 48; Ł. Myszka, Dominikanie w Toruniu: od fundacji do kasaty, in: Nowe Miasto Toruń, S. 179-180; T. Jasiński, Przedmieścia średniowiecznego Torunia i Chetmna, (1982), S. 51 (St. Laurentius-Kapelle), S. 52-53 (Heilig-Kreuz-Kirche und Heilig-Geist-Kirche), S. 56-57 (Rockendorf-Kapelle); A. Semrau, Die Neustadt Thorn während ihrer Selbständigkeit 1264-1454, (Mitteilungen des Coppernicus-Vereins für Wissenschaft und Kunst zu Thorn 37, 1929), S. 38 (St. Katharina-Kirche); grundlegende Informationen zu den drei Klöstern Thorns: Franziskaner, Dominikaner und Zisterzienserinnen-Benediktinerinnen, mit Verweisen auf einschlägige Literatur, bei: M. Biskup, Średniowieczna sieć klasztorów w państwie Zakonu Krzyżackiego w Prusach (do 1525 r.), in: Zakony i klasztory w Europie Środkowo-Wschodniej X-XX w., hg. v. H. Gapski, J. Kłoczowski, (1999), S. 58 (Dominikaner), 59-60 (Franziskaner), 62 (Zisterzienserinnen-Benediktinerinnen). $\mathrm{Zu}$ Zisterzienserinnen-Benediktinerinnen siehe: M. Olesińska, Benedyktynki w Toruniu: od fundacji do kasaty, in: Nowe Miasto Toruń, S. 216-221; zu den Beginenhäusern und Hospital sowie Kapelle zu St. Peter und Paul siehe: P. Oliński, Fundacje mieszczańskie w miastach pruskich w okresie średniowiecza i na progu czasów nowożytnych (Chełmno, Toruń, Elbląg, Gdańsk, Królewiec, Braniewo), (2008), S. 451-454; siehe auch M. Sumowski, Duchowni diecezjalni w średniowiecznym Toruniu. Studium prozopograficzne, (2012), S. 21-45. 
urbis ambiunt"? Ein Teil dieser Kirchen und Klöster war schließlich intra muros gelegen, die sonstigen extra muros. Die Rolle dieser loca sanctorum war natürlich die Erfüllung der liturgischen und seelsorgerischen Funktionen. Sie spielten somit in dem religiösen Leben der Thorner Bürger die Schlüsselrolle ${ }^{4}$. Genauso wichtig war aber die Rolle, welche die Schutzherren dieser loca sanctorum spielten, obwohl uns nicht bekannt ist, inwieweit sich die damalige Gemeinschaft dessen bewusst war. Sie bestand in dem geistigen Schutz der Stadt vor verschiedenen Angriffen und Begehrlichkeiten zahlreicher Feinde, wobei die Gläubigen diese Aufgabe mit ihrem Gebet stark unterstützten. Die erwähnten Sakralobjekte wurden mit ihren Patronen zu symbolischen, geistigen Stadtschützern (defensores civitatis). Die Analyse der Kirchenpatrone dieser Objekte in der Alt- und Neustadt Thorn zeigt, dass sich die meisten geistlichen Schutzherrschaften von Kirchen, Klöstern, Kapellen und Hospitälern aus den populärsten im ganzen Ordensstaat in Preußen rekrutierten. Dies waren St. Georg, St. Nikolaus, Jungfrau Maria, St. Johannes der Täufer und St. Johannes Evangelist, St. Katharina, St. Laurentius, St. Peter und Paul ${ }^{5}$. Diesen Schutzherren wurde auch der geistige Schutz der Alt- und Neustadt Thorn anvertraut. Es ist kein Zufall, dass in einer der mittelalterlichen Predigten des Avitus von Vienne zu lesen ist: „Ornantur oppida non minus aedibus quam patronis [...]“ („Die Städte werden nicht nur mit Gotteshäusern, sondern auch durch ihre Schutzherren verziert"). Diesen Schutzherren wurde, zumindest durch die Vertreter der Elite der mittelalterlichen Gesellschaft, die ganz pragmatische Aufgabe zugewiesen, die städtische Gemeinschaft vor zahlreichen Gefahren zu schützen ${ }^{6}$. Erwähnenswert ist hier auch die sakrale und architektonische Sicherheit des städtischen

4 R. Czaja, Życie religijne mieszczaństwa toruńskiego $w X V w$., „Rocznik Toruński“, 18 (1988), S. 217-240; siehe auch: A. Radzimiński, Wiara, praktyki religijne, religijność, in: Państwo zakonu krzyżackiego w Prusach. Gospodarka i kultura, (im Druck).

5 W. Rozynkowski, Omnes sancti et sanctae Dei. Studium nad kultem świętych w diecezjach pruskich państwa zakonu krzyżackiego, (2006), S. 176-178.

6 I. Crusius, Basilicae muros urbis ambiunt. Zum Kollegiatstift des frühen und hohen 
Raumes der nacheinander gegründeten Alt- und Neustadt Thorn und auch, oder vor allem, die Einstellung des Deutschen Ordens zu den religiösen Bedürfnissen ihrer Bewohner ${ }^{7}$. Es war immerhin kein Zufall, dass schon in den Dreißigerjahren des 13. Jahrhunderts, gleich nach der ersten Gründung der Altstadt Thorn, die zwei wichtigsten sakralen Objekte entstanden, nämlich die Pfarrkirche zu St. Johannes dem Täufer und St. Johannes Evangelist innerhalb der ursprünglichen Stadt und die Marienkirche samt Franziskanerkloster (1239) - damals noch außerhalb der städtischen Mauern gelegen ${ }^{8}$.

Die Aufgaben dieser ersten Thorner Mendikanten-Niederlassung scheinen mit der klassischen These von Jacques Le Goff übereinzustimmen, der feststellte, die Bettelorden wählten für ihre Stiftungen bewusst Stadtränder, Vorstädte, die in die Pfarrstrukturen noch nicht inkludiert waren, bewohnt von der neu angekommenen Dorfbevölkerung, die der Seelsorge bisher entzogen waren ${ }^{9}$. Ein anderes Modell der architektonischen Sakralisierung des städtischen Raumes ist seit den Sechzigerjahren des 13. Jahrhunderts in der Neustadt Thorn zu beobachten, wo, diesmal noch vor der Ausgabe eines Gründungsdokuments für diese Stadt und sicherlich einige Jahrzehnte vor der Gründung der

Mittelalters in deutschen Bischofsstädten, in: Studien zum weltlichen Kollegiatstift in Deutschland, hg. v. I. Crusius, (1995), S. 9-34.

7 Dazu siehe H. Manikowska, Miasta i mieszczaństwo na ziemiach Polski w średniowieczu - postulaty i perspektywy badawcze, in: Pytania o średniowiecze. Potrzeby i perspektywy badawcze polskiej mediewistyki, hg. v. W. Fałkowski, (2001), S. 118.

8 J. Tandecki, Założenie i początki klasztoru franciszkanów toruńskich w XIII-XIV w. , ZZapiski Historyczne“, 54, 4 (1989), S. 7-22. Zu der Kirche siehe Z. Nawrocki, Pofranciszkański kościół NMP w Toruniu. Próba rekonstrukcji dziejów budowy, (Zeszyty Naukowe UMK, Nauki humanistyczno-społeczne. Zabytkoznawstwo i konserwacja 21, 1966), S. 47-80; idem, Pofranciszkański kościót Wniebowzięcia Najświętszej Marii Panny w Toruniu, (1995); J. Domasłowski, J. Jarzewicz, Kościół Najświętszej Marii Panny $w$ Toruniu, (1998).

9 J. Le Goff, Apostolat mendiant et fait urbain dans la France médiévale, limplantation des ordres mendiants. Programme-questionnaire pour une enquête, „Annales E.S.C.“, 23 (1968), S. 337. 
Pfarrei zu St. Jakobus Apostel ${ }^{10}$, am 2. April 1263 Hochmeister Anno von Sangerhausen das Dominikanerkloster stiftete und gleichzeitig den Dominikanern den Bau der St. Nikolai-Kirche gestattete ${ }^{11}$. Es war wohl eine der besten Investitionen im Bereich Seelsorge für die dortigen Bewohner, welche die Deutschordensritter je tätigten. Die Dominikaner waren ein Predigerorden, sie widmeten sich besonders einer intensiven Seelsorge- und Predigertätigkeit. Auf diese Tätigkeit waren sie auch viel besser vorbereitet als der lokale Pfarrklerus, insbesondere auf dem Dorf ${ }^{12}$.

Die Kloster-Geografie des mittelalterlichen Thorn vervollständigen Deutschordens-Stiftungen, realisiert im 14. Jahrhundert. Die erste bezog sich auf die Benediktinerinnen, deren Kloster ursprünglich extra muros stand, anfänglich am Heilig-Geist-Hospital in der Weichsel-Vorstadt angesiedelt, dann wurde es an der Heilig-Kreuz-Kirche platziert, in die Kulmer Vorstadt nördlich von Alt-Thorn verlegt. Letztlich ließen sie sich nach 1414, nach dem Zusammenschluss mit den Zisterzienserinnen, wieder beim Heilig-Geist-Hospital in der Weichsel-Vorstadt nieder. Die zweite Stiftung betraf die Zisterzienserinnen, die seit der Mitte des 14. Jahrhunderts bei der erwähnten St. Jakobs-Pfarrkirche residierten, um nach dem Zusammenschluss mit den Benediktinerinnen ihr Haus bei dem bereits erwähnten Heilig-Geist-Hospital zu finden ${ }^{13}$. Hinzuzufügen sei, dass sich die Rolle der ZisterzienserinnenBenediktinerinnen hauptsächlich auf pflegerisch-erzieherische und

10 L. Krantz-Domasłowska, J. Domasłowski, Kościół świętego Jakuba w Toruniu, (2001); Sumowski, Duchowni diecezjalni, s. 31-35.

11 Preussisches Urkundenbuch. Politische Abteilung (weiter: Pr. Urk.), hg. v. R. Philippi, 1 (1882), Nr. 197; T. Jasiński, Początki klasztoru dominikańskiego w Toruniu, „Zapiski Historyczne“, 54, 4 (1989), S. 23f.; Myszka, Dominikanie w Toruniu, S. 178-180.

12 Vgl. die Lage im mittelalterlichen Krakau: K. Ożóg, Klasztorna geografia średniowiecznego Krakowa, in: Klasztor w mieście średniowiecznym i nowożytnym, hg. v. M. Derwicha, A. Pobóg-Lenartowicz, (2000), S. 217-234.

13 Glemma, Dzieje, S. 262-263; Biskup, Średniowieczna, S. 62; Sumowski, Duchowni diecezjalni, S. 26-38. 
schulische Tätigkeiten beschränkte. Die Zielgruppe waren Töchter des lokalen Bürgertums und der hiesigen Adeligen, gewöhnlich gegen reichliche Legate zugunsten des Klosters ${ }^{14}$.

Seelsorgerische Aufgaben für die nördlichen Vorstädte erfüllte bis zur Mitte des 14. Jahrhunderts (Privileg des Hochmeisters Heinrich Dusemer vom 7. Dezember 1349) die Heilig-Kreuz-Kapelle mit Friedhof, gelegen bei der St. Laurentius-Kirche und dem Hospital, die damals dem Pfarrer der Johanniskirche untergeordnet waren ${ }^{15}$. Die Seelsorge für Leprakranke lag im Zuständigkeitsbereich der St. Georgs-Kirche, gelegen an dem Leprosorium weiter im Norden der Stadt. Der Patron dieser Kirche war auch der Betreuer derjenigen, welche Folter und Leiden geduldig aushielten, in diesem Falle waren das unheilbar Kranke ${ }^{16}$. Ähnliche Funktionen erfüllte darüber hinaus die ebenfalls im nördlichen Teil der Vorstädte von Alt-Thorn gelegene St.-Laurentius-Kirche ${ }^{17}$. Das Zeichen einer immer mehr individualisierteren Frömmigkeit, aber auch des Wohlstandes, war die Privatkapelle der wohlhabenden Familie Rockendorf, die seit der zweiten Hälfte des 14. Jahrhunderts existierte ${ }^{18}$.

Die Pfarrkirchen organisierten im Mittelalter verschiedene Formen des religiösen wie auch des weltlichen Lebens. Das Letztgenannte

14 Eine derartige Spende in Höhe von 6 Mark leistete im Jahre 1411 der damalige Bürgermeister der Altstadt Thorn Johann von der Mersche für die Aufnahme seiner Tochter Gertrud in das Kloster. Thorner Denkwürdigkeiten von 1345-1547, hg. v. A. Voigt, (Mitteilungen des Coppernicus-Vereins für Wissenschaft und Kunst zu Thorn 13, 1904), S. 42 („Herr Johann v. der Mersche giebt mit seiner Tochter Gertrud, damit Sie in das Nonnenkloster, ausserhalb der Stadt an der Weichsel gelegen möge aufgenommen werden, 6 mrc. Zinses alle Jahr und versichert solche auf Herrn v. Putten Hause, in der BeckerGasse gelegen“).

15 Pr. Urk., 4: (1346-1351), hg. v. H. Koeppen, (1960), Nr. 483; Jasiński, Przedmieścia, S. 51; R. Czaja, Rozwój szpitali miejskich w państwie zakonu krzyżackiego $w$ Prusach, in: Szpitalnictwo w dawnej Polsce, hg. v. M. Dąbrowska, J. Kruppe, (1998), S. 142; Sumowski, Duchowni diecezjalni, S. 40-42.

16 Czaja, Rozwój, S. 140; Sumowski, Duchowni diecezjalni, S. 38-40.

17 Jasiński, Przedmieścia, S. 56.

18 Ibidem, S. 56-57; Sumowski, Duchowni diecezjalni, S. 42-43. 
bestand u.a. in der Nutzung der Gotteshäuser und der anliegenden Parzellen für weltliche Zwecke, z. B. für Handel ${ }^{19}$. Es ist auch kein Zufall, dass in der Thorner Johanniskirche die Wahl der Stadtoberhäupter und andere Versammlungen des lokalen Bürgertums stattfanden. Die altstädtischen Räte und ihre Gemahlinnen hatten darüber hinaus unter entsprechenden Bedingungen (auch finanziellen) das Recht, in der Krypta der Johanniskirche begraben zu werden ${ }^{20}$. Die Bedeutung der Pfarrkirche St. Johannes des Täufers und St. Johannes Evangelist in der Altstadt Thorn ergab sich aus ihrem relativ umfangreichen Landbesitz (44 Huben), verliehen durch die Ordensritter, wovon sowohl die Kulmer Handfeste aus dem Jahre 1233 und $1251^{21}$ als auch z. B. das Lebensniveau und somit das Niveau der Einkünfte der verwaltenden Pfarrer zeugten. Die von Johann von Ast, dem Pfarrer der Johanniskirche, um die Mitte des 15. Jh. geführten Rechnungen sind uns sehr gut bekannt. Johann von Ast entstammte einer in Köln sesshaften italienischen Familie, genoss eine hervorragende Ausbildung und absolvierte die juristische Fakultät der Universität in Bologna ${ }^{22}$. Die Rechnungen illustrieren Ausgaben, die von diesem Geistlichen innerhalb von knapp einem Jahr getätigt wurden (Mai 1445 bis Januar 1446), vor allem für

19 Über das Handelsverbot in Kirchen und auf dem anliegenden Gelände ist in der Landessatzung aus dem Jahre 1420 zu lesen: „Auch sal man keynen kouffman adir kramer uff dem kirchhoeffe adir yn der kirchen keynerleye ware lassen veil haben“. Acten der Ständetage Preussens unter der Herrschaft des Deutschen Ordens (weiter AST), hg. v. M. Toeppen, 1 (1874), Nr. 286, S. 350, Ziffer 17.

20 Thorner Denkwürdigkeiten, S. 14 („Hoc anno floruit Reverendus Luberthus Wachsloger, Parochus Thorunensis, qui concessit, ut Procons et Consules Thorunenses et eorum uxores, tum omnes alii, qui pro fabrica illius templi Parochialis manum porrexerunt, in eodem sepelirentur": Jahr 1388), S. 19, 35, 38, 41, 52, 62.

21 Pr. Urk., 1, Nr. 105, 252; K. Zielińska-Melkowska, Przywilej chetmiński 1233 i 1251. Teksty pomników prawa chetmińskiego w przekładach polskich, (1983).

22 Geheimes Staatsarchiv Preussischer Kulturbesitz Berlin-Dahlem, Ordensbriefarchiv, Nr. 9226 [Jahres-Rechnung des Pfarrers zu Thorn], Blatt 1-16; Diese Rechnungen wurden von A. Radzimiński herausgegeben: Rachunki plebana kościoła parafialnego Świętych Janów w Starym Mieście Toruniu z lat 1445-1446, „Roczniki Historyczne“, 69 (2003), S. 167-187. 
verschiedenartige Lebensmittel, sowohl für Feierlichkeiten als auch für das Alltagsleben, Treffen mit eingeladenen Gästen oder Aufwendungen für Reisen. Johann von Ast gab in der Sommerzeit erhebliche Summen aus, z. B. im Juli 1445 verbrauchte er 151/2 Mark und 39 Denare, also insgesamt 11.199 Denare. Dies ist sehr viel, insbesondere, wenn man z. B. die Tagessätze von Gesellen bedenkt, die ca. 20 Denare betrugen, also monatlich maximal 600 Denare. Noch höher fielen die Ausgaben dieses Geistlichen in der Winterzeit aus. Im Dezember, also in der Zeit wichtiger Feste, betrugen sie das Doppelte, d. i. knapp 30 Mark, also 21.600 Denare ${ }^{23}$. Es ist also nicht erstaunlich, dass das Pfarrhaus der Johanniskirche eins der einträglichsten kirchlichen Benefizien bildete, und dies nicht nur in der Altstadt Thorn, sondern allgemein im Deutschordensterritorium Preußen. Und selbst dann, wenn die Erträge dieser Kirche, ähnlich wie jene von der Marienkirche in der Rechtstadt Danzig, direkt in die Kasse des Hochmeisters gezahlt werden sollten. Leider, wie es oft im Mittelalter war, entsprachen die Bezüge des Pfarrers nicht seinem seelsorgerischen Engagement. Da der Deutsche Orden in diesem Bereich das Patronatsrecht hatte, war das Pfarrhaus der Johanniskirche in der Kreuzritterzeit ausschließlich mit Priesterbrüdern besetzt, die sich vorher Kanzleiaufgaben bzw. politischer oder diplomatischer Tätigkeiten für den Hochmeister widmeten ${ }^{24}$. Es sei betont, dass das ordensritterliche Patronatsrecht über Pfarrkirchen eines der wichtigsten Elemente der Macht des Ordens in Preußen war ${ }^{25}$. Dieses Privileg behielt er sich nicht nur in Hinsicht auf die große

23 Dazu detailliert A. Radzimiński, Przy stole Jana von Ast - plebana św. Janów w Starym Mieście Toruniu, „Archeologia Historica Polona“, 14 (2004), S. 157-171.

24 Z. H. Nowak, Sposoby werbowania intelektualistów do zakonu krzyżackiego w Prusach w pierwszej połowie XV w., "Zapiski Historyczne“, 45, 2 (1980), S. 103; R. Czaja, Deutscher Orden und Stadtklerus in Preussen im Mittelalter, in: Ritterorden und Kirche im Mittelalter, „Ordines militares. Colloquia Torunensia Historica“, 9 (1997), S. 83,85 .

25 M. Dygo, Studia nad początkami władztwa zakonu niemieckiego w Prusach (1226-1259), (1992), S. 243. 
Mehrheit der städtischen Pfarrkirchen in Preußen vor, sondern auch hinsichtlich der dort gestifteten Hospitäler und Nonnenklöster ${ }^{26}$. Auch das Pfarrbenefizium der Johanniskirche in der Altstadt Thorn erhielten oft, insbesondere nach der ersten Schlacht bei Tannenberg, Geistliche zugewiesen, die früher an der Spitze der Kanzlei des Hochmeister standen oder Geistliche, die mit dem Deutschen Orden auf andere Art und Weise verbunden waren. Im Regelfall waren sie ausgezeichnet ausgebildet, mit einer guten politischen und diplomatischen Vorbereitung ${ }^{27}$. Man darf dabei nicht vergessen, dass die Ordensregel sowie die dort herrschenden Statuten die Geistlichen, und noch weniger die Ritterbrüder, keinesfalls zum Universitätsstudium verpflichteten ${ }^{28}$. Mehr noch, erst im Jahre 1422 erlaubte der damalige Papst Martin V. den Brüdern des Deutschen Ordens, ein juristisches Studium aufzunehmen und akademische Grade zu erwerben ${ }^{29}$. Bis zur Mitte des 15. Jahrhunderts unterstützte der Orden aber schon 44 Jurastudenten finanziell, von denen viele erst nach Abschluss des Studiums Mitglieder des Deutschen Ordens wurden ${ }^{30}$.

Von den bekannten Pfarrern der Johanniskirche aus der ersten Hälfte des 15. Jahrhunderts sind zu nennen Nikolaus Meinecke (1416-1420), früher Kaplan des Hochmeisters Michael Küchmeister, Andreas Pfaffendorf (1425-1433), Student an der Prager Karls-Uni-

\section{Czaja, Deutscher Orden, S. 82.}

27 Ibidem, S. 93; s. auch Fußnote 28 und 39.

28 K. Militzer, Beziehungen des Deutschen Ordens zu den Universitäten, besonders zur Kölner Universität, in: Die Spiritualität der Ritterorden im Mittelalter. Ordines militares. Colloquia Torunensia Historica, hg. v. Z. H. Nowak, 7 (1993), S. 254ff.; Neudruck in: K. Militzer, Zentrale und Region. Gesammelte Beiträge zur Geschichte des Deutschen Ordens in Preußen, Livland und im Deutschen Reich aus den Jahren 1968 bis 2008, (Quellen und Studien zur Geschichte des Deutschen Ordens 75), (2015), S. 236 ff.

${ }^{29}$ H. Blaese, Rechtsschulen des Deutschen Ordens - eine Legende, „Zeitschrift für Ostforschung", 6, 2 (1957), S. 273ff.

30 H. Boockmann, Die Rechtsstudenten des Deutschen Ordens. Studium, Studienförderung und gelehrter Beruf im späteren Mittelalter, in: Festschrift für H. Heimpel zum 70. Geburtstag, 2 (1972), S. 31ff. 
versität, der Hochschulen in Wien und Bologna, wo er im Jahre 1421 in Kirchenrecht promovierte ${ }^{31}$, Nikolaus Salomonis (1433-1435), Kaplan des Hochmeisters Paul von Rusdorf, Johann Sobbe (1435-1437), Doktor der Theologie an der Universität Leipzig und Dozent an der italienischen Universität von Bologna oder der schon erwähnte Johann von Ast (1438-1449), Absolvent der juristischen Fakultät von Bologna. Eine wunderbare Zusammensetzung aus Intellektuellen und Geistlichen, die in politischen Maßnahmen des Ordens stark engagiert waren, die aber aus diesem Grunde der Seelsorge und der Liturgie in der uns interessierenden Kirche sehr wenig Zeit widmeten. Deswegen wurden diese Geistlichen durch den lokalen Bischof mehrmals gemahnt. In Bezug auf die Pfarrer der Thorner Johanniskirche irrte sich der Autor der Synodalpredigt auch nicht. Bei der Synode zu Elbing 1427 kritisierte er diese Gruppe der Geistlichen für die mangelnde Betreuung ihrer Gläubigen ${ }^{32}$. Geirrt hat er sich aber, zumindest in Bezug auf die in der Thorner Johanniskirche amtierenden Pfarrer, als er sie der geringen Bildung beschuldigte ${ }^{33}$. Eine bedeutende Rolle im Bereich der Seelsorge dürfte also, wie zu erwarten ist, dem niedrigeren, oft anonymen, um die Johanniskirche versammelten Klerus zuteil geworden sein - den Vizepfarrern, Kaplänen, Vikaren oder Predigern. Es wird geschätzt, dass

31 T. Borawska, Preussische Jura-Studenten an italienischen Universitäten, in: Von Preußenland nach Italien. Beiträge zur Kultur- und bildungsgeschichtlichen Vernetzung europäischer Regionen, hg. v. M. Mersiowsky, A. Menzel-Reuters, (Innsbrucker Historische Studien 30, 2015), S. 100.

32 O. Günter, Eine Predigt vom preußischen Provinzialkonzil in Elbing 1427 und die „Ermahnung des Carthäusers“, „Zeitschrift des Westpreußischen Geschichtsvereins“, 59 (1919), S. 99 („Et multe negligencie sunt apud clerum in aliquibus in amministrando sacramenta"); siehe S. Kwiatkowski, Klimat religijny $w$ diecezji pomezańskiej u schyłku XIV $i$ w pierwszych dziesięcioleciach XV w., (1990), S. 177.

33 Günter, Eine Predigt, S. 101 („Heu quam magnum malum oritur ex negligencia, aliquando ex avaricia examinatoris et scriptoris, quod multi ydeote et indigni ad ordines sacros promoventur! [...] Ecclesie dei sepe reguntur per ydeotas, legem dei, canones atque statuta episcoporum omnino ignorantes“); siehe Kwiatkowski, Klimat, S. 177. 
die dortigen niedrigeren Benefizien die wirtschaftliche Grundlage für die Aktivität von ca. 70 Geistlichen waren ${ }^{34}$. Obwohl der Deutsche Orden auf die Besetzung des Pfarrbenefiziums der Johanniskirche einen wesentlichen Einfluss hatte und obwohl sein Vermögen mit den dazu gehörigen Ländereien und wichtigerem Mobiliar noch im Jahre 1393 dem Eigentum der Ordensritter auf dem Gebiet der Komturei Thorn zugerechnet wurde, wurde dem Stadtrat der Altstadt Thorn der Einfluss auf das soziale und religiöse Leben um die Johanniskirche doch nicht völlig entzogen ${ }^{35}$. Der Einfluss wurde, insbesondere im späteren Mittelalter, immer bedeutender, beispielsweise durch die Kirchenväter (kirchenvetter, vorweser), welche eine Art Pfarrbeirat gebildet haben. Bekannt sind sie spätestens seit dem Jahre 1351 (der erste, über den in den Quellen zu lesen ist, war der Stadtrat Tideman Pape) ${ }^{36}$, obwohl wir wissen, dass auch schon früher der Stadtrat über wichtige Investitionen in der Kirche entscheiden konnte ${ }^{37}$. Spätestens in der zweiten Hälfte des 14. Jahrhunderts wurde ein besonderer Fonds gebildet, fabrica ecclesiae genannt, und hauptsächlich für die Bau- und Renovierungsarbeiten in der Kirche bestimmt war ${ }^{38}$. Sicherlich unterlag er schon damals nicht dem Ordenspfarrer, sondern wurde durch die erwähnten Kirchenväter verwaltet. Diese wurden wiederum schon in der zweiten Hälfte des 15. Jahrhunderts (Verweise aus den Jahren 1468 und 1472 in dem Mietbuch der Johanniskirche) ausschließlich durch den Stadtrat gewählt ${ }^{39}$. Zu den Zuständigkeiten der Kirchenväter gehörten

34 Glemma, Dzieje, S. 263; siehe Radzimiński, Rachunki plebana, S. 180, 184.

35 Das grosse Ämterbuch des Deutschen Ordens, hg. v. W. Ziesemer, (1921), S. 460-462.

36 M. Arszyński, Stosunki między zakonem krzyżackim a społeczeństwem w świetle rozważań nad organizacja budowy kościołów parafialnych w Prusach, in: Zakon krzyżacki a społeczeństwo państwa w Prusach, hg. v. Z. H. Nowak, (1995), S. 176.

37 Thorner Denkwürdigkeiten, S. 6.

38 Ibidem, S. 14; siehe Arszyński, Stosunki, S. 176

39 K. Steinbrecht, Thorn im Mittelalter, (1885), S. 27; siehe Arszyński, Stosunki, S. 177; vgl. zu den Aufgaben der Kirchenväter in der Jacobs-Kirche M. Sumowski, 
darüber hinaus Mieten, die der Pfarrkirche zugewiesen wurden, und die Beaufsichtigung der Beschlüsse des Stadtrates gegebenenfalls der preußischen Stände, welche sich auf das religiöse Leben der Thorner Bürger bezogen ${ }^{40}$. In der Historiographie wird stark betont, dass die entscheidende Rolle für Ausbau und Renovierung dieser Kirche eben der Stadtrat Thorns gehabt habe und nicht die Pfarrer oder der Patron der Johanniskirche, also der Deutsche Orden.

Der Stadtrat organisierte und finanzierte auch die Bauarbeiten, die schon in der Mitte des 15. Jahrhunderts, also noch zu Ordenszeiten, unternommen wurden ${ }^{41}$. Die Aufseher über das kirchliche Vermögen, die durch den Rat der Altstadt Thorn ernannt wurden, waren in dem untersuchten Zeitraum bekannte Bürgermeister der Stadt: Albrecht Rote (erwähnt 1412) ${ }^{42}$, Johann Huxer (erwähnt 1433) ${ }^{43}$, Gotschalk Hitfeld (erwähnt 1451, 1454-1455) ${ }^{44}$, Rotcher Birken (erwähnt 1453) ${ }^{45}$ oder der hervorragende Stadtrat Konrad Teudenkus (erwähnt 1451) ${ }^{46}$. Infolge des Zweiten Friedens von Thorn aus dem Jahre 1466, welcher den Dreizehnjährigen Krieg beendete, unterstellte sich das Kulmer Land mit Thorn der Krone Polens als Kulmer Wojewodschaft, welche einen Teil von Königlich-Preußen bildete. Das Bistum Kulm, nachdem dem Domkapitel in den Jahren 1471-1479 durch den Bischof Wincenty Gosławski (genannt Kiełbasa), nach Einwilligung des Papstes Sixtus IV., der Charakter einer weltlichen Korporation wiederverliehen worden

Rachunki witryka kościoła św. Jakuba w Toruniu z 1468 r., in: Parafie w średniowiecznych Prusach w czasach zakonu niemieckiego od XIII do XVI w., hg. v. R. Biskup, A. Radzimiński, (2015), S. 237-272.

40 Thorner Denkwürdigkeiten, S. 114, 131; AST, 2, S. 365, 618.

41 Ausführlich zu diesem Thema Arszyński, Stosunki, S. 175-177.

42 R. Czaja, Urzędnicy miejscy Torunia do roku 1454. Spisy, (1999), S. 219.

43 Księga ławnicza Starego Miasta Torunia (nachstehend: KŁSMT), 1-2, hg. v. K. Ciesielska, J. Tandecki, (1992-1993); Teil 1, Nr. 335; siehe Czaja, Urzędnicy, S. 206.

44 KŁSMT, Teil 2, Nr. 1764; siehe Czaja, Urzędnicy, S. 204.

45 Czaja, Urzędnicy, S. 197.

46 KŁSMT, Teil 2, Nr. 1584; siehe Czaja, Urzędnicy, S. 224. 
war, stand unter dem Einfluss der polnischen Kirche. Die politischkirchlichen Wandlungen, die mit der Beseitigung des Deutschen Ordens verbunden waren, wirkten sich auch auf gewisse Weise auf die Pfarrkirche St. Johannes des Täufers und St. Johannes Evangelist aus. Zuerst, am 26. August 1457, also noch während des Dreizehnjährigen Krieges, behielt sich König Kasimir (der Jagiellone) in einem großen Privileg für Thorn das Patronat über die Johannis-Pfarrkirche vor ${ }^{47}$. Aber schon im Jahre 1505, genauer seit dem Privileg des polnischen Königs Alexander des Jagiellonen, sollte das dortige Pfarrbenefizium abwechselnd durch den polnischen König und durch den Stadtrat von Thorn besetzt werden ${ }^{48}$. Es ging in die Hände von hochgebildeten Geistlichen, die sehr oft eben mit dem schon damals säkularisierten Kulmer Domkapitel verbunden waren.

Die Verbindungen der Pfarrer von der Johanniskirche mit der dortigen Korporation zeigen deutlich, wie bedeutend der Einfluss der damaligen Kulmer Bischöfe auf die Besetzung dieser Kirche war. Nennenswert sind an der Stelle die hervorragendsten Pfarrer der damaligen Johanniskirche, die sich mit ihrer Kirche sowohl im Bereich der Seelsorge als auch der Stifte viel stärker identifiziert haben als ihre Vorgänger, die Ordensgeistlichen. Zweifelsohne war es Hieronimus Waldau (1466-1495), Kanoniker in Ermland und Kulm sowie Offizial des Kulmer Bischofs. Dieser Pfarrer der Johanniskirche zeigte historisches Interesse und verzeichnete auf den Rändern des Buches von Enea Silvio Piccolomini Familiares epistole ad diversos Notizen über die Ereignisse in Thorn, im Kulmer Bistum und in Preußen. Er stiftete auch die Pfründe am Hauptaltar ${ }^{49}$. Sein Nachfolger war Johann

47 AST, 4, Nr. 385.

48 Staatsarchiv in Toruń, Kat. I, Nr. 2702; siehe auch: A. Radzimiński, J. Tandecki, Katalog dokumentów i listów królewskich $z$ Archiwum Państwowego $w$ Toruniu (1345-1789), (1999), Nr. 149.

49 Sein Biogramm siehe A. Mańkowski, Prałaci i kanonicy katedralni chełmińscy. Od założenia kapituły do naszych czasów, „Roczniki TNT“, 34 (1927), S. 393; Słownik Biograficzny Kapituły Warmińskiej, (1996), S. 268 (erarbeitet v. T. Borawska); zu der 
Schmolle (1496-1512), ein Thorner Bürger, ausgebildet an der Universität Leizpig, der früher Kulmer Kanoniker (1485) und Kanzler des Kulmer Bischofs Stefan von Neidenburg war. Auch dieser Pfarrer an der Johanniskirche war ein großzügiger Stifter für seine Kirche, indem er ein Legat für den Prediger stiftete, der gleichzeitig die Funktion des Altaristen am Altar der Marienkirche ausüben sollte. Bereits in der Zeit, als er das Amt des Pfarrers bekleidete, wurde im Turm der Kirche die große Glocke „Tuba Dei“ aufgehängt ${ }^{50}$. Nach 1513 wurde Raphael Wayner zum Pfarrer der Johanniskirche bestellt, er war Kaplan des Kulmer Bischofs Mikołaj Chrapicki und Kulmer Kanoniker (seit 1497), später Offizial dieses Bischofs. Auch er hat eines der Benefizien in seiner Kirche (St.-Regina-Kirche) gestiftet ${ }^{51}$.

Von der Entwicklung des religiösen Lebens, und auf jeden Fall auch über die breite stifterische Aktivität des mittelalterlichen Bürgertums, zeugen u.a. zahlreiche Schenkungen, welche die Sakraltopografie

Stiftung der Pfründe in der Johanniskirche siehe die Quellenedition: K. Górski, M. Gołembiowski, Wykaz prebend kościelnych Torunia z 1541 r., „Zapiski Historyczne“, 42, 4 (1977), S. 152 („Primum beneficium sive ministerium sub titulo sanctorum Joannis Baptistae et Evangelistae in summo altari. Est erectum beneficium. Ius patronatus habet Senatus una cum plebano. Fundatum a venerabili domino Ieronimo Waldaw olim canonico Warmiensis et Culmensis Ecclesiarum et parocho praefate Parochialis Ecclesiae pro seniori capellano sive sit Almanus vel Polonus"); siehe M. Sumowski, Ego Jeronimus Waldau.. O tożsamości późnośredniowiecznego plebana toruńskiego, „Zapiski Historyczne“, 79, 1 (2014), S. 63-81.

50 Sein Biogramm erarbeitet von Mańkowski, Prałaci, 34, S. 374, 424 und neulich P. Oliński, in: Toruński Słownik Biograficzny, 1 (1998), S. 219-220. Zur Stiftung des Benefiziums: Quellenedition von Górski, Gołembiowski, Wykaz, S. 169 („Vicesimum octavum beneficium sub titulo beatae Virginis Mariae fundatum a venerabili domino Ioanne Smolle olim canonico Culmensi et sancti Ioannis parochialis ecclesiae in Thorun plebano. Fundavit pro praedicatore dictae ecclesiae ita tamen, quod etiam inserviet huic altari ad quod optima ornata comparavit et habet censos certos scilicet $30 \mathrm{mrc}$. de praetorio vel Senatu").

51 Sein Biogramm erarbeitet von Mańkowski, Prałaci, 2, S. 396-397; zur Stiftung des Benefiziums in der Johanniskirche siehe die Edition von Górski, Gołembiowski, Wykaz, S. 168 („Vicesimum sextum beneficium sub titulo sanctae Reginae erectum, fundatum a Venerabili Domino Raphaele Weyner olim canonico Culmensi“). 
der Pfarrkirche St. Johannes des Täufers und St. Johannes Evangelist ausmachten. Insgesamt gab es dort 8 Kapellen und 11 Altäre, in denen 31 Vikarien bestellt wurden. Der Stadtrat hatte das Recht auf das Patronat über 12 Pfründen, trotzdem wurden sie im Grunde durch herausragende Stadtbürger gestiftet. Die weiteren 15 Benefizien, die in der Johanniskirche aufgerichtet wurden, gehörten zu dem Patronat der bürgerlichen Stifter, die weiteren 4 wiederum der dortigen Konfraternitäten. Unter den Stiftern der Benefizien in der Johanniskirche sind auch bekannte Stadtbürgerinnen zu nennen: z. B. Dorota Armknecht (sie stiftete die St. Katharina-Vikarie) ${ }^{52}$, Katharina Watzenrode (St. Elisabeth-Benefizium ${ }^{53}$, bedeutende bürgerliche Familien: Familie Teschner (Vikarie an dem St. Anna-Altar) ${ }^{54}$, Familie Vasan (die zweite Vikarie am St. Anna-Altar) ${ }^{55}$, Familie Putten, Becker und von Allen (erste Vikarie in der St. Andreas-Kapelle) ${ }^{56}$, Familie vom Lo (die dritte

52 Górski, Gołembiowski, Wykaz, S. 154 („Quartum beneficium sub titulo sanctae Katherinae fundatum a quadam muliere Dorothea cognominata Armknechtynne est erectum beneficium [...]"); siehe ihr Biogramm erarbeitet von K. Ciesielska, Toruński Słownik Biograficzny, 1 (1998), S. 22-23; mehr zu ihrer Stiftungs- und Wohlfahrtsaktivität P. Oliński, Fundacje i legaty religijne kobiet świeckich $w$ wielkich miastach pruskich, in: Kobieta i rodzina w średniowieczu i na progu czasów nowożytnych, hg. v. Z. H. Nowak, A. Radzimiński, (1998), S. 154-155; idem, Fundacje mieszczańskie, S. 204-205.

53 Górski, Gołembiowski, Wykaz, S. 155 („Septimum beneficium sub titulo sanctae Elisabeth fundatum primo ab honesta domina Katherina Watzenrodynne“); zu ihrer Genealogie siehe K. Mikulski, Watzenrodowie i kapituła warmińska. Rola związków rodzinnych $w$ duchownych karierach mieszczan torunskich $w$ XIV i XV wieku, in: Homines et societas. Czasy Piastów i Jagiellonów, (1997), S. 359-371; Oliński, Fundacje mieszczańskie, S. 199-200.

54 Górski, Gołembiowski, Wykaz, S. 157; zu den von Teschners in der Altstadt Thorn bekleideten Ämtern siehe K. Mikulski, Urzędnicy miejscy Torunia 1454-1650. Spisy, (2001), S. 211-212; Oliński, Fundacje mieszczańskie, S. 205.

55 Górski, Gołembiowski, Wykaz, S. 158; zu den Angehörigen dieser Familie siehe Czaja, Urzędnicy, S. 200; Mikulski, Urzędnicy, S. 191; Oliński, Fundacje mieszczańskie, S. 206.

56 Górski, Gołembiowski, Wykaz, S. 165; zu den Vertretern dieser Familien in Thorner Ämtern siehe Czaja, Urzędnicy, S. 195-196, 216; Mikulski, Urzędnicy, S. 185, 187; Oliński, Fundacje mieszczańskie, S. 194-195. 
Vikarie in der St. Andreas-Kapelle) ${ }^{57}$, oder Rockendorf (Benefizium am St. Michael-Altar $)^{58}$, aber auch Kulmer Kanoniker, z. B. Kasper Welker (Vikarie am St. Wolfgang-Altar) ${ }^{59}$.

Zusammenfassend ist $\mathrm{zu}$ betonen, dass die vorgenannten in der Johanniskirche gestifteten Altarbenefizien die Sakraltopografie dieser Kirche wunderbar mitgestalteten. Sie brachten über 700 Mark Jahreseinkommen, welches samt dem reichlichen Benefiziumseinkommen des Pfarrers der Johanniskirche eine gute Grundlage für die liturgische Arbeit und Seelsorge bildete, die eine zahlreiche Gruppe von Geistlichen in dem besprochenen Gotteshaus zugunsten der Thorner Bürger unternahmen. Diese Aktivitäten machten immerhin die Ausstattung des schönen gotischen Gotteshauses mit seiner einzigartigen Verzierung aus.

Übersetzt von Edyta Grotek

\section{KOŚCIÓ PARAFIALNY ŚW. JANA CHRZCICIELA \\ I ŚW. JANA EWANGELISTY W TOPOGRAFII SAKRALNEJ MIASTA TORUNIA W ŚREDNIOWIECZU}

\section{(STRESZCZENIE)}

Artykuł prezentuje kościół parafialny śś. Janów w Starym Mieście Toruniu na tle topografii sakralnej Starego i Nowego Miasta Torunia w okresie średniowiecza. Ukazuje rolę plebanów tego kościoła w działalności duszpasterskiej i liturgicznej oraz ich relacje z radą Starego Miasta Torunia. Wskazuje ponadto na rolę witryków, którzy tworzyli swego rodzaju radę parafialną, w życiu tego kościoła parafialnego.

57 K. Górski, M. Gołembiewski, Wykaz, S. 165; zu den Vertretern der Familie vom Lo siehe Czaja, Urzędnicy, S. 211; Mikulski, Urzędnicy, S. 200; Oliński, Fundacje mieszczańskie, S. 194-195

58 Górski, Gołembiowski, Wykaz, S. 166; zu den Vertretern dieser Familie in den Ämtern in Thorn siehe Czaja, Urzędnicy, S. 218; Mikulski, Urzędnicy, S. 205; Oliński, Fundacje mieszczańskie, S. 205.

59 Górski, Gołembiowski, Wykaz, S. 160 („Decimum quartum beneficium sub titulo sancti Wolffgangi primi ministerii fundatum a venerabili domino Caspare Wilker olim canonico Culmensi“); Oliński, Fundacje mieszczańskie, S. 206. 


\section{DIE PFARRKIRCHE ST. JOHANNES DES TÄUFERS UND ST. JOHANNES DES EVANGELISTEN IN DER SAKRALTOPOGRAFIE DER STADT THORN IM MITTELALTER}

\section{(ZUSAMMENFASSUNG)}

Der Beitrag stellt die Pfarrkirche St. Johannes des Täufers und St. Johannes des Evangelisten in der Sakraltopografie der Alt- und Neustadt Thorns im Mittelalter dar. Er zeigt die Rolle der Pfarrer dieser Kirche in der seelsorgerischen und liturgischen Tätigkeit sowie das Verhältnis zum Rat der Altstadt Thorn. Er zeigt auch die Rolle der Kirchenväter, welche eine Art Pfarreibeirat gebildet haben, im Leben der Pfarrkirche.

Übersetzt von

Renata Skowrońska

\section{THE PARISH CHURCH OF SS. JOHN THE BAPTIST AND JOHN THE EVANGELIST IN THE SACRED TOPOGRAPHY OF THE CITY OF TORUŃ IN THE MIDDLE AGES}

\section{(SUMMARY)}

The article presents the parish church of SS. Johns in the Old Town of Torun as against the sacred topography of the Old and New City of Torun in the Middle Ages. It shows the role of parish priests of this church in the pastoral and liturgical activity along with their relations with the Council of the Old City of Torun. It indicates the role of parish priests in the functioning of this parish church.

Translated by

Agnieszka Chabros

\section{Słowa kluczowe / Schlagworte / Keywords}

- topografia sakralna miast; budynki sakralne; prawo patronatu; proboszcz; duchowieństwo parafialne; fundacje zakonu krzyżackiego i mieszczaństwa

- sakrale Topografie der Stadt; sakrale Gebäude; Patronatsrecht; Pfarrer; Pfarrklerus; Stiftungen durch den Deutschen Orden und Stadtbürger

- sacred topography of towns; sacred buildings; the right of patronage; parish priest; parish clergy; foundations of the Teutonic Order and the burgess 


\section{BIBLIOGRAFIA / BIBLIOGRAFIE / BIBLIOGRAPHY}

\section{ŹRÓDŁA ARCHIWALNE / ARCHIVALISCHE QUELLEN / ARCHIVAL SOURCES}

Geheimes Staatsarchiv Preußischer Kulturbesitz in Berlin-Dahlem, Ordensbriefarchiv, Nr. 9226 [Jahres-Rechnung des Pfarrers zu Thorn], Blatt 1-16.

\section{ŹRÓDłA DRUKOWANE / GEDRUCKTE QUELLEN / PRINTED SOURCES}

Acten der Ständetage Preussens unter der Herrschaft des Deutschen Ordens, 1-5,

hg. v. M. Toeppen, (1874-1888).

Das grosse Ämterbuch des Deutschen Ordens, hg. v. W. Ziesemer, (1921).

Günter O., Eine Predigt vom preußischen Provinzialkonzil in Elbing 1427 und die „Ermahnung des Carthäusers“, „Zeitschrift des Westpreußischen Geschichtsvereins", 59 (1919), S. 94-111.

Księga ławnicza Starego Miasta Torunia, 1-2, hg. v. K. Ciesielska, J. Tandecki, (1992-1993).

Preussisches Urkundenbuch. Politische Abteilung, 1, hg. v. R. Philippi, (1882).

Radzimiński A., Tandecki J., Katalog dokumentów i listów królewskich z Archiwum Państwowego w Toruniu (1345-1789), (1999).

Thorner Denkwürdigkeiten von 1345-1547, hg. v. A. Voigt, (Mitteilungen des Coppernicus-Vereins für Wissenschaft und Kunst zu Thorn 13, 1904).

\section{LITERATURA / LITERATUR / LITERATURE}

Arszyński M., Stosunki między zakonem krzyżackim a społeczeństwem w świetle rozważań nad organizacją budowy kościołów parafialnych w Prusach, in: Zakon krzyżacki a społeczeństwo państwa w Prusach, hg. v. Z. H. Nowak, (1995), S. 165-184.

Biskup M., Średniowieczna sieć klasztorów w państwie Zakonu Krzyżackiego w Prusach (do 1525 r.), in: Zakony i klasztory w Europie Środkowo-Wschodniej $X-X X$ w., hg. v. H. Gapski, J. Kłoczowski, (1999).

Blaese H., Rechtsschulen des Deutschen Ordens - eine Legende, „Zeitschrift für Ostforschung", 6, 2 (1957), S. 273-293.

Boockmann H., Die Rechtsstudenten des Deutschen Ordens. Studium, Studienförderung und gelehrter Beruf im späteren Mittelalter, in: Festschrift für $H$. Heimpel zum 70. Geburtstag, 2 (1972), S. 313-375.

Borawska T., Preussische Jura-Studenten an italienischen Universitäten, in: Von 
Preußenland nach Italien. Beiträge zur Kultur- und bildungsgeschichtlichen Vernetzung europäischer Regionen, hg. v. M. Mersiowsky, A. Menzel-Reuters, (Innsbrucker Historische Studien 30, 2015).

Crusius I., Basilicae muros urbis ambiunt. Zum Kollegiatstift des frühen und hohen Mittelalters in deutschen Bischofsstädten, in: Studien zum weltlichen Kollegiatstift in Deutschland, hg. v. I. Crusius, (1995).

Czaja R., Deutscher Orden und Stadtklerus in Preussen im Mittelalter, in: Ritterorden und Kirche im Mittelalter. Ordines militares. Colloquia Torunensia Historica, 9, hg. v. Z. H. Nowak, (1997), S. 81-96.

Czaja R., Rozwój szpitali miejskich w państwie zakonu krzyżackiego w Prusach, in: Szpitalnictwo w dawnej Polsce, hg. v. M. Dąbrowska, J. Kruppe, (1998), S. 135-144.

Czaja R., Urzędnicy miejscy Torunia do roku 1454. Spisy, (1999).

Czaja R., Życie religijne mieszczaństwa toruńskiego w XV w., „,Rocznik Toruński“, 18 1988), S. 217-240.

Domasłowski J., Jarzewicz J., Kościół Najświętszej Marii Panny w Toruniu, (1998). Dygo M., Studia nad początkami władztwa zakonu niemieckiego w Prusach (1226-1259), (1992).

Fankidejski J., Utracone kościoły i kaplice $w$ dzisiejszej diecezji chełmińskiej, (1873).

Glemma T., Dzieje stosunków kościelnych w Toruniu, in: Dzieje Torunia, hg. v. K. Tymieniecki, (1933), S. 259-266.

Le Goff J., Apostolat mendiant et fait urbain dans la France médiévale, l'implantation des ordres mendiants. Programme-questionnaire pour une enquête, „Annales E.S.C.“, 23 (1968).

Górski K., Gołembiowski M., Wykaz prebend kościelnych Torunia z 1541 r., „Zapiski Historyczne“, 42, 4 (1977).

Historia Torunia, hg. v. M. Biskup, 1: W czasach średniowiecza (do roku 1454), erarbeitet v. J. Chudziakowa (et al.), und 2: U schytku średniowiecza $i$ w poczatkach odrodzenia (1454-1548), erarbeitet v.. M. Biskup, (1992, 1999). Jähnig B., Das Entstehen der mittelalterlichen Sakraltopographie von Elbing, „Beiträge zur Geschichte Westpreußens“, 10 (1987), S. 21-48.

Jähnig B., Die Anfänge der Sakraltopographie von Riga, in: Studien über die Anfänge der Mission in Livland, hg. v. M. Hellmann, (1989), S. 123-158.

Jähnig B., Die Entwicklung der Sakraltopographie von Memel im Mittelalter und in der frühen Neuzeit, in: Das Preussenland als Forschungsaufgabe. Eine europäische Region in ihren geschichtlichen Bezügen. Festschrift für Udo Arnold zum 60. Geburtstag, (Einzelschriften der Historischen Kommission 
für ost- und westpreußische Landesforschung 20),hg. v. B. Jähnig, G.Michels, (2000), S. 209-226.

Jasiński T., Początki klasztoru dominikańskiego w Toruniu, „Zapiski Historyczne“, 54, 4 (1989), S. 23-48.

Jasiński T., Przedmieścia średniowiecznego Torunia i Chełmna, (1982).

Krantz-Domasłowska L., Domasłowski J., Kościół świętego Jakuba w Toruniu, (2001).

Kwiatkowski S., Klimat religijny $w$ diecezji pomezańskiej u schyłku XIV i w pierwszych dziesięcioleciach XV w., (1990).

Manikowska H., Miasta i mieszczaństwo na ziemiach Polski w średniowieczu postulaty i perspektywy badawcze, in: Pytania o średniowiecze. Potrzeby i perspektywy badawcze polskiej mediewistyki, hg. v. W. Fałkowski, (2001).

Mańkowski A., Prałaci i kanonicy katedralni chełmińscy. Od założenia kapituły do naszych czasów, „Roczniki TNT“, 34 (1927), S. 285-424.

Mikulski K., Przestrzeń i społeczeństwo Torunia od końca XIV do początku XVIII w., (1999).

Mikulski K., Urzędnicy miejscy Torunia 1454-1650. Spisy, (2001).

Mikulski K., Watzenrodowie i kapituła warmińska. Rola związków rodzinnych $w$ duchownych karierach mieszczan torunskich $w$ XIV i XV wieku, in: Homines et societas. Czasy Piastów i Jagiellonów, (1997), S. 359-371.

Militzer K., Beziehungen des Deutschen Ordens zu den Universitäten, besonders zur Kölner Universität, in: Die Spiritualität der Ritterorden im Mittelalter. Ordines militares. Colloquia Torunensia Historica, 7, hg. v. Z. H. Nowak, (1993), S. 253-269; Neudruck in: K. Militzer, Zentrale und Region. Gesammelte Beiträge zur Geschichte des Deutschen Ordens in Preußen, Livland und im Deutschen Reich aus den Jahren 1968 bis 2008, (Quellen und Studien zur Geschichte des Deutschen Ordens 75), (2015), S. 236-250.

Nawrocki Z., Pofranciszkański kościół NMP w Toruniu. Próba rekonstrukcji dziejów budowy, (Zeszyty Naukowe UMK, Nauki humanistyczno-społeczne. Zabytkoznawstwo i konserwacja 21, 1966), S. 47-80.

Nawrocki Z., Pofranciszkański kościół Wniebowzięcia Najświętszej Marii Panny $w$ Toruniu, (1995).

Nowak Z. H., Sposoby werbowania intelektualistów do zakonu krzyżackiego $w$ Prusach $w$ pierwszej połowie XV w., „Zapiski Historyczne“, 45, 2 (1980), S. 101-106.

Nowe Miasto Toruń. 750 lat od lokacji, hg. v. K. Mikulski, P. Oliński, W. Rozynkowski, (2014).

Oliński P., Fundacje i legaty religijne kobiet świeckich $w$ wielkich miastach prus- 
kich, in: Kobieta i rodzina w średniowieczu i na progu czasów nowożytnych, hg. v. Z. H. Nowak, A. Radzimiński, (1998), S. 143-159.

Oliński P., Fundacje mieszczańskie w miastach pruskich $w$ okresie średniowiecza i na progu czasów nowożytnych (Chełmno, Toruń, Elbląg, Gdańsk, Królewiec, Braniewo), (2008).

Ożóg K., Klasztorna geografia średniowiecznego Krakowa, in: Klasztor w mieście średniowiecznym i nowożytnym, hg. v. M. Derwicha, A. Pobóg-Lenartowicz, (2000), S. 217-234.

Radzimiński A., Przy stole Jana von Ast - plebana św. Janów w Starym Mieście Toruniu, „Archeologia Historica Polona“, 14 (2004), S. 157-171.

Radzimiński A., Rachunki plebana kościoła parafialnego Świętych Janów w Starym Mieście Toruniu z lat 1445-1446, „Roczniki Historyczne“, 69 (2003), S. 167-187.

Rozynkowski W., Omnes sancti et sanctae Dei. Studium nad kultem świętych $w$ diecezjach pruskich państwa zakonu krzyżackiego, (2006).

Słownik Biograficzny Kapituly Warmińskiej, (1996).

Steinbrecht K., Thorn im Mittelalter, (1885).

Sumowski M., Duchowni diecezjalni w średniowiecznym Toruniu. Studium prozopograficzne, (2012).

Sumowski M., Ego Jeronimus Waldau... O tożsamości późnośredniowiecznego plebana toruńskiego, „Zapiski Historyczne“, 79, 1 (2014), S. 63-81.

Sumowski M., Rachunki witryka kościoła św. Jakuba w Toruniu z 1468 r., in: Parafie w średniowiecznych Prusach w czasach zakonu niemieckiego od XIII do XVI w., hg. v. R. Biskup, A. Radzimiński, (2015), S. 237-272.

Tandecki J.,Założenie i początki klasztoru franciszkanów toruńskich w XIII-XIV w., „Zapiski Historyczne“, 54, 4 (1989), S. 7-22. 


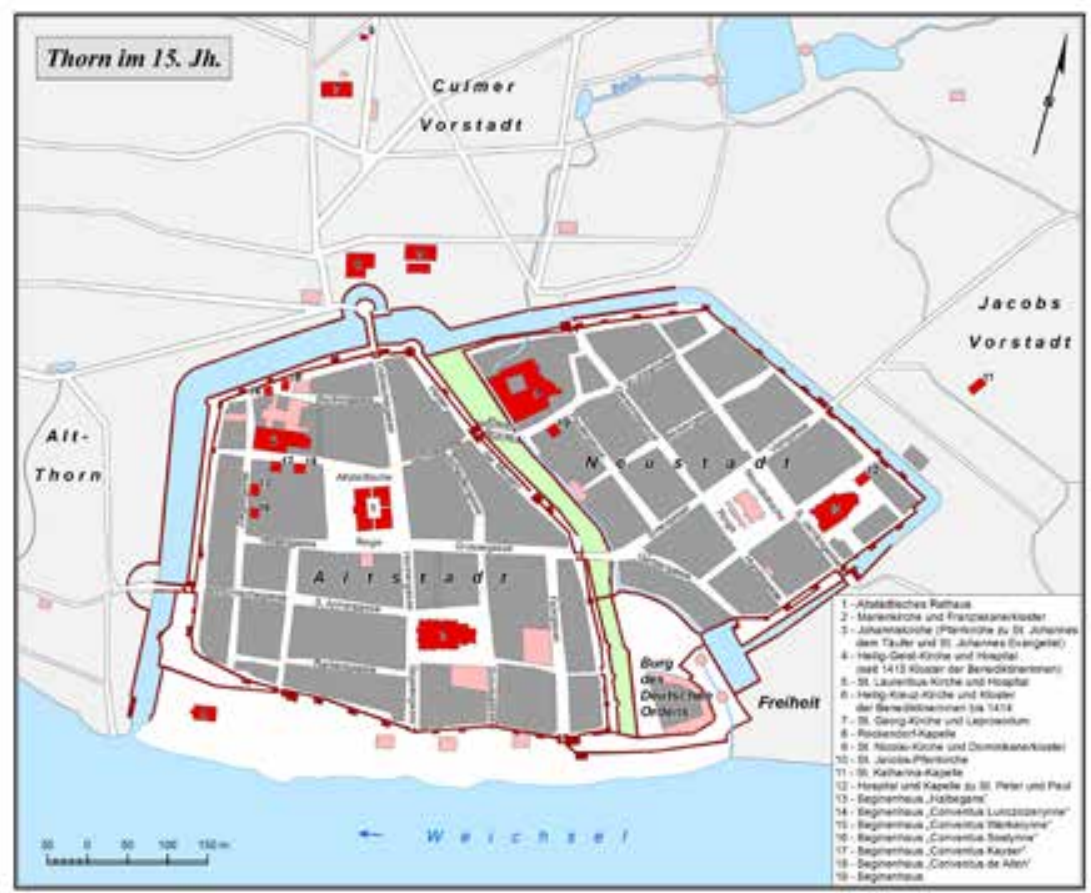

Plan der Stadt Thorn im 15. Jahrhundert (bearb. Radosław Golba und Andrzej Radzimiński) 
